\title{
(2) OPEN ACCESS \\ Post-COVID-19 paediatric inflammatory multisystem syndrome: association of ethnicity, key worker and socioeconomic status with risk and severity
}

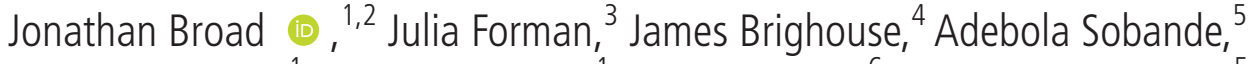 \\ Alysha McIntosh, ${ }_{1}$ Claire Watterson, ${ }_{1}^{1}$ Elizabeth Boot, ${ }^{6}$ Felicity Montgomery, ${ }_{1}^{5}$ \\ Iona Gilmour, ${ }^{5}$ Joy Tan, ${ }^{5}$ Mary Johanna Fogarty, ${ }_{1}^{7}$ Xabier Gomez, ${ }^{6}$ Ronny Cheung (i) , \\ Jon Lillie (1) ${ }^{6}$ Vinay Shivamurthy, ${ }^{4}$ Jenny Handforth, ${ }^{1}$ Owen Miller (1) , ${ }^{7}$ PIMS-TS study \\ group
}

\begin{abstract}
- Additional material is published online only. To view, please visit the journal online (http://dx.doi.org/10.1136/ archdischild-2020-320388).

For numbered affiliations see end of article.
\end{abstract}

Correspondence to Dr Jonathan Broad, Paediatric infectious disease, Evelina London Children's Healthcare, London SE1 7EH, UK; jonathanb.broad@gmail.com

Received 5 August 2020 Revised 13 February 2021 Accepted 21 February 2021 Published Online First 16 March 2021
Check for updates

(C) Author(s) (or their employer(s)) 2021. Re-use permitted under CC BY-NC. No commercial re-use. See rights and permissions. Published by BMJ.

To cite: Broad J, Forman J, Brighouse J, et al.

Arch Dis Child

2021;106:1218-1225.

\begin{abstract}
Objectives Patients from ethnic minority groups and key workers are over-represented among adults hospitalised or dying from COVID-19. In this populationbased retrospective cohort, we describe the association of ethnicity, socioeconomic and family key worker status with incidence and severity of Paediatric Inflammatory Multisystem Syndrome Temporally associated with SARSCoV-2 (PIMS-TS).
\end{abstract}

Setting Evelina London Children's Hospital (ELCH), the tertiary paediatric hospital for the South Thames Retrieval Service (STRS) region.

Participants 70 children with PIMS-TS admitted 14 February 2020-2 June 2020.

Outcome measures Incidence and crude ORs are presented, comparing ethnicity and socioeconomic status of our cohort and the catchment population, using census data and Index of Multiple Deprivation (IMD). Regression is used to estimate the association of ethnicity and IMD with admission duration and requirement for intensive care, inotropes and ventilation. Results Incidence was significantly higher in children from black (25.0 cases per 100000 population), Asian $(6.4 / 100000)$ and other (17.8/100 000) ethnic groups, compared with 1.6/100 000 in white ethnic groups (ORs $15.7,4.0$ and 11.2 , respectively). Incidence was higher in the three most deprived quintiles compared with the least deprived quintile (eg, 8.1/100 000 in quintile 1 vs $1.6 / 100000$ in quintile $5, O R$ 5.2). Proportions of families with key workers (50\%) exceeded catchment proportions. Admission length of stay was 38\% longer in children from black ethnic groups than white $(95 \%$ Cl $4 \%$ to $82 \%$; median 8 days vs 6 days). 9/10 children requiring ventilation were from black ethnic groups. Conclusions Children in ethnic minority groups, living in more deprived areas and in key worker families are over-represented. Children in black ethnic groups had longer admissions; ethnicity may be associated with ventilation requirement.

This project was registered with the ELCH audit and service evaluation team, ref. no 11186.

\section{INTRODUCTION}

In children, COVID-19 infection is mostly asymptomatic or the cause of a mild respiratory illness, ${ }^{1}$

\section{What is already known on this topic?}

SARS-CoV-2 appears to be less severe and to lead to fewer hospital admissions in children compared with adults. In the adult population, ethnicity, key worker status and socioeconomics impact the severity and risk of COVID-19 disease. Paediatric Inflammatory Multisystem Syndrome, Temporally associated with SARSCoV-2 (PIMS-TS) is a novel disease associated with COVID-19 disease, and case series suggest ethnicity may be a factor in children.

\section{What this study adds?}

We characterise the associations of ethnicity and socioeconomic deprivation with risk and severity of PIMS-TS in a cohort of children living in the South Thames Retrieval Service referring region, a large region in South East England. We found a higher risk for PIMS-TS and some evidence for markers of more severe illness for children living in postcodes with higher socioeconomic deprivation and in children from ethnic minority groups. These results should be interpreted with caution, given the novel and rare nature of this disease, and the preliminary analysis presented here would benefit from prospective, larger multicentre analyses.

with low risk of mortality. ${ }^{2}$ A novel disease has emerged, presumed to represent a postviral immune-mediated hyperinflammatory response to COVID-19 infection, ${ }^{3}$ termed Paediatric Inflammatory Multisystem Syndrome, Temporally associated with SARS-CoV-2 (PIMS-TS), ${ }^{4}$ or Multisystem Inflammatory Syndrome in Children (MIS-C). ${ }^{56}$ It shares features with Kawasaki disease, including persistent fever, elevated inflammatory markers, cutaneous and conjunctival changes. ${ }^{7}$ Both can lead to cardiovascular shock, coronary aneurysms and death. The epidemiological risk factors are 


\begin{tabular}{|c|c|c|}
\hline Age 3 months- 16 years & Number $(n=70)$ & Percentage \\
\hline \multicolumn{3}{|l|}{ Gender } \\
\hline Female & 21 & 30 \\
\hline Male & 49 & 70 \\
\hline \multicolumn{3}{|l|}{ Socioeconomic status } \\
\hline Quintile 1 (most deprived) & 15 & 21 \\
\hline Quintile 2 & 24 & 34 \\
\hline Quintile 3 & 18 & 25 \\
\hline Quintile 4 & 8 & 11 \\
\hline Quintile 5 (least deprived) & 5 & 7 \\
\hline \multicolumn{3}{|l|}{ Ethnicity } \\
\hline White & 18 & 26 \\
\hline Mixed & 4 & 6 \\
\hline Asian/Asian-British & 7 & 10 \\
\hline Black/African/Caribbean/black British & 38 & 54 \\
\hline Other - any other ethnic group & 3 & 4 \\
\hline \multicolumn{3}{|l|}{ Body mass index } \\
\hline$>25$ & 11 & 16 \\
\hline$\leq 25$ & 59 & 84 \\
\hline
\end{tabular}

undetermined, yet case series into this Kawasaki-like syndrome suggest the potential contribution of ethnicity. ${ }^{8}$

In adult COVID-19, infection rates and severity are higher in people from ethnic minority groups, in men and in those living in socioeconomically deprived areas. ${ }^{9}$ Age-standardised death rates in the least deprived decile, were 17 and 35.9 per 100000 population for women and men, respectively. In comparison, in the most deprived decile, the rates were 39.6 and 76.7 per 100000 for women and men, respectively. ${ }^{9}$ Ethnicity remains a significant risk factor for infection after controlling for socioeconomics, household factors and comorbidities. ${ }^{10} 11$ In England and Wales, incidence of COVID-19 was 486 and 649 per 100 000 population in black ethnic groups, for women and men, respectively, compared with 220 and 224 per 100000 in white ethnic groups, for women and men, respectively. ${ }^{9}$ Death rates for people from black, Asian and minority ethnic (BAME) groups were two to four times higher during the current COVID-19 pandemic than expected versus one to two times higher rates in white ethnic groups. ${ }^{9}$

In PIMS-TS, the majority of patients were from ethnic minority groups in case series, though studies lacked controls. ${ }^{18}{ }^{12} 13 \mathrm{In}$ studies of Kawasaki disease, ethnicity, socioeconomic deprivation, urban residence and population density contributed to a

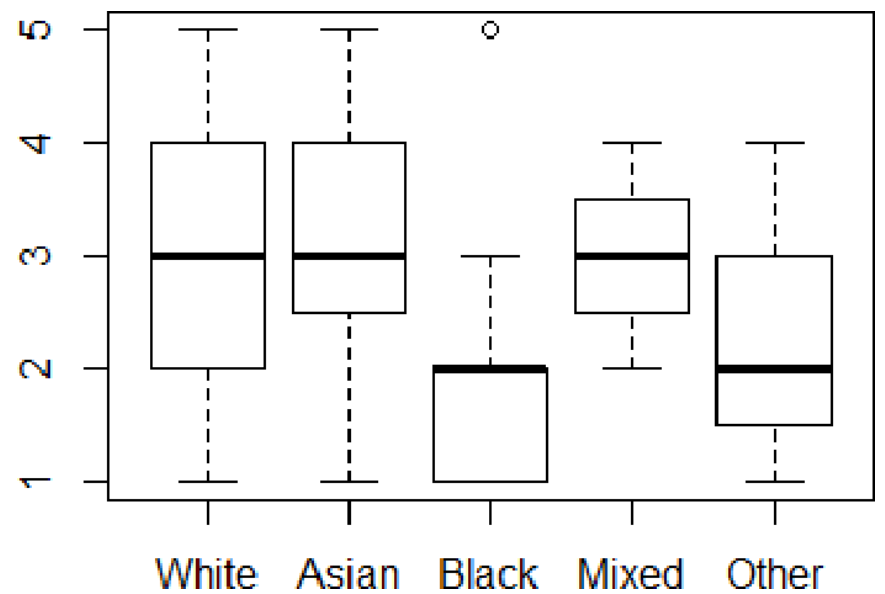

Figure 1 IMD quintiles by ethnic group. higher risk. In England and Wales, people in black ethnic groups constitute $13 \%$ of the population but $20 \%$ of Kawasaki patients in certain studied areas; patients of Chinese and Japanese heritage were also at higher risk. ${ }^{14} 15$

In this population-based retrospective cohort, we describe ethnicity, socioeconomic status, geography and family key worker status in PIMS-TS and their association with risk and severity.

\section{METHODS}

Ethics

As the data analysis was retrospective and no additional data were collected beyond that required for standard medical care of the patient, a full ethics review under the terms of the Governance Arrangements of Research Ethics Committees in the UK was not required.

\section{Study design}

This is an observational retrospective cohort study using Office for National Statistics (ONS) data and anonymised clinical data of all inpatient children at the Evelina London Children's Hospital (ELCH) that were diagnosed with PIMS-TS from 14 March 2020 to 2 June 2020. This method conformed to established guidelines. ${ }^{16}$

\section{Patient-level inclusion and exclusion criteria}

All included patients $(n=70)$ were prospectively diagnosed with PIMS-TS by a paediatric multidisciplinary team (MDT), comprising specialists from infectious diseases and immunology, intensive care, rheumatology, cardiology and general paediatrics. The MDT diagnosed hyperinflammation in some patients prior to formal case definitions being published. Diagnosis was based on clinical features plus biochemical evidence of inflammation. Children were excluded with alternative primary diagnoses or if PIMS-TS treatment was discontinued. PIMS-TS cases that did not meet Royal College of Paediatrics and Child Health (RCPCH) criteria are included as suspected PIMS-TS. A secondary analysis (see online supplemental appendix) was conducted on the subset who met the RCPCH PIMS-TS definition; the main findings were unchanged.

The population for our comparator data was age under 16 years, in the South Thames Retrieval Service (STRS) referring region, namely South London, Surrey, East Sussex and Kent. For the incidence analysis, the patients were included if under 16 years and resident in the STRS referring region to match the population-level comparator data.

\section{Case definitions}

The three published case definitions for PIMS-TS/MIS-C from $\mathrm{RCPCH}$, Centers for Disease Control and Prevention and WHO were used to classify patients against diagnostic criteria. Classifications vary with regards to fever definition, organ dysfunction and exposure to SARS-CoV-2. After collecting prospectively, all cases were reviewed retrospectively (by IG, FM and JT) to classify whether they met each criteria, using electronic patient records.

\section{Dependent variables}

Severity data were collected from electronic patient records. Coronary dilatation was defined as a Z-score $>2.0$ on transthoracic echocardiography ${ }^{17}$ with all studies reviewed by a consultant paediatric cardiologist. Illness severity was assessed by length of admission and requirement for critical care, inotropes 
Table 2 Crude ORs and 95\% CIs for PIMS-TS by IMD quintile and ethnicity (STRS referring region only, under 16 years only, $\mathrm{n}=63 *$ )

\begin{tabular}{|c|c|c|c|c|c|c|c|c|}
\hline & $\mathrm{N}$, cohort & $\%$, cohort & $\mathrm{N}$, population & $\%$, population & Rate per 100000 & OR estimate & $95 \% \mathrm{Cl}$ & $P$ value \\
\hline \multicolumn{9}{|l|}{ IMD } \\
\hline Quintile 1 & 15 & 24 & 185365 & 14 & 8.1 & 5.2 & 1.9 to 14.3 & 0.0014 \\
\hline Quintile 2 & 22 & 35 & 300958 & 22 & 7.3 & 4.7 & 1.8 to 12.4 & 0.0018 \\
\hline Quintile 3 & 15 & 24 & 276896 & 20 & 5.4 & 3.5 & 1.3 to 9.6 & 0.0158 \\
\hline Quintile 4 & 6 & 10 & 277762 & 20 & 2.2 & 1.4 & 0.4 to 4.5 & 0.5894 \\
\hline Quintile 5 & 5 & 8 & 320936 & 24 & 1.6 & 1 & & \\
\hline \multicolumn{9}{|l|}{ Ethnicity } \\
\hline White & 15 & 24 & 942267 & 73 & 1.6 & 1 & & \\
\hline Black & 35 & 56 & 140014 & 11 & 25 & 15.7 & 8.6 to 28.7 & $<0.0001$ \\
\hline Asian & 6 & 10 & 94094 & 7 & 6.4 & 4 & 1.6 to 10.3 & 0.0041 \\
\hline Mixed & 4 & 6 & 100718 & 8 & 4 & 2.5 & 0.8 to 7.5 & 0.1043 \\
\hline Other & 3 & 5 & 16851 & 1 & 17.8 & 11.2 & 3.2 to 38.6 & 0.0001 \\
\hline
\end{tabular}

${ }^{*}$ Three patients of the 70 years were excluded due to self-referring from out of network, and four patients were excluded due to age.

IMD, Index of Multiple Deprivation; PIMS-TS, Paediatric Inflammatory Multisystem Syndrome, Temporally associated with SARS-CoV-2 ; STRS, South Thames Retrieval Service.

or invasive ventilatory support. Invasive ventilation included intubation, mechanical ventilation or extracorporeal membrane oxygenation.

\section{Cohort and regional demographic data}

The Index of Multiple Deprivation 2019 (IMD) at Lower-level Superoutput Area (LSOA) of the patients' residence was used as a proxy marker for socioeconomic deprivation. ${ }^{18}$ Complete patient postcodes were matched to LSOA to assign an IMD quintile for each patient. The under-16 populations per quintile were derived from the IMD population denominators data set, ONS estimates relating to the midpoint of 2017.

Ethnicity was determined by parents as recorded on electronic patient records using standardised National Health Service (NHS) categories. Comparator ethnicity data were aggregated from the local authority level using census data. ${ }^{19}$ One extra ethnicity group in census data (white gypsy/traveller), was not part of NHS data, so it was incorporated in other white.

Patient-level data on key worker status was collected from patients' families. For the population-level cohort, data on key workers from January 2019 to December 2019 were taken from ONS and presented for comparison, using government-defined standard occupational classification. ${ }^{20}$ Cumulative COVID-19 infection incidence rates per population group in England within ethnic groups were collected from Public Health England (17 June 2020), and hospitalisation data (15 March 2020-26 June 2020) were taken from a recent biobank study. ${ }^{21} 22$ Healthcare worker comparison data were taken from NHS England workforce. $^{23}$

Table 3 ORs by ethnicity for PIMS-TS, and COVID-19 infections and hospitalisations

\begin{tabular}{lccc}
\hline $\begin{array}{l}\text { Ethnicity } \\
\text { group }\end{array}$ & PIMS-TS* & $\begin{array}{l}\text { England COVID-19 } \\
\text { infectionst }\end{array}$ & Hospitalisation₹ \\
\hline White & $*$ & $*$ & $*$ \\
\hline Black & $15.7(8.6$ to 28.7$)$ & $1.39(1.36$ to 1.43$)$ & $4.32(3.00$ to 6.23$)$ \\
Asian & $4.0(1.6$ to 10.3$)$ & $1.22(1.20$ to 1.24$)$ & $2.12(1.37$ to 3.28$)$ \\
Mixed & $2.5(0.8$ to 7.5$)$ & $0.52(0.50$ to 0.54$)$ & - \\
\hline Other & $11.2(3.2$ to 38.6$)$ & $2.79(2.71$ to 2.86$)$ & $1.84(1.13$ to 2.99$)$ \\
\hline
\end{tabular}

*ORs from incidence of the PIMS-TS cohort presented here.

†COVID-19 cumulative infection incidence as defined by PCR positive test from Public Health England until 17 June $2020 .^{22}$

¥Hospitalisation for COVID-19: those admitted to hospital in biobank study with COVID-19 symptoms and confirmed COVID-19 on PCR, taken from Lassale et al, ${ }_{1}^{21}$ age-adjusted and sex-adjusted ORs (from 15 March 2020 to 26 April 2020).

PIMS-TS, Paediatric Inflammatory Multisystem Syndrome, Temporally associated with SARS-CoV-2.

\section{Statistical analyses}

Crude ORs were estimated by ethnic group (reference group white) and by IMD quintile (reference group quintile 5, least deprived) to describe the representation of the cohort, relative to the hospital catchment area. Key worker status is descriptive, due to lack of an equivalent population-based comparator.

Length of stay was analysed using linear regression to estimate the association with independent variables: ethnicity, IMD quintile, body mass index (BMI; fitted as a continuous variable), age and gender. Length of stay was log-transformed for analysis due to a positively skewed distribution; resulting estimates have been antilog transformed. Binary clinical severity measures (paediatric intensive care unit (PICU), admission, ventilation and inotrope use) were analysed using logistic regression, with the same independent variables (ethnicity, IMD quintile, BMI, age and gender). The results were antilog transformed, presented as ORs. All regression models were fitted treating IMD quintile as a linear covariate and as an ordinal covariate. For each outcome, full multivariate regression models with all independent variables was evaluated, and compared, using a likelihood ratio test, to models with all of the independent variables except ethnicity to assess improvement of fit.

Analyses were conducted using statistical software R (V.3.4.1) and RStudio (V.1.0.143). ${ }^{24}{ }^{25} \mathrm{P}$ values were considered significant below the 0.05 level. We had complete data for all participants and therefore, there were no missing data.

\section{RESULTS}

\section{Clinical features}

Seventy patients were diagnosed with PIMS-TS by the MDT, summarised in table 1 . Fifty-seven met the RCPCH case definition (see online supplemental appendix). Forty-six patients were admitted to PICU, 32 required inotropes, 10 required ventilation and 1 died. For the 13 patients who were MDTdiagnosed but did meet RCPCH criteria, eight did not meet criteria due to secondary diagnoses, predominantly coinfection with Escherichia coli, MSSA, EBV, adenovirus, parainfluenza or because the fever was not persistent. There were minimal biochemical or cardiac differences between those who met diagnostic criteria and those who did not (online supplemental appendix). Demographic features and the relationship between IMD quintile and ethnicity are presented (table 1 and figure 1 , respectively). 


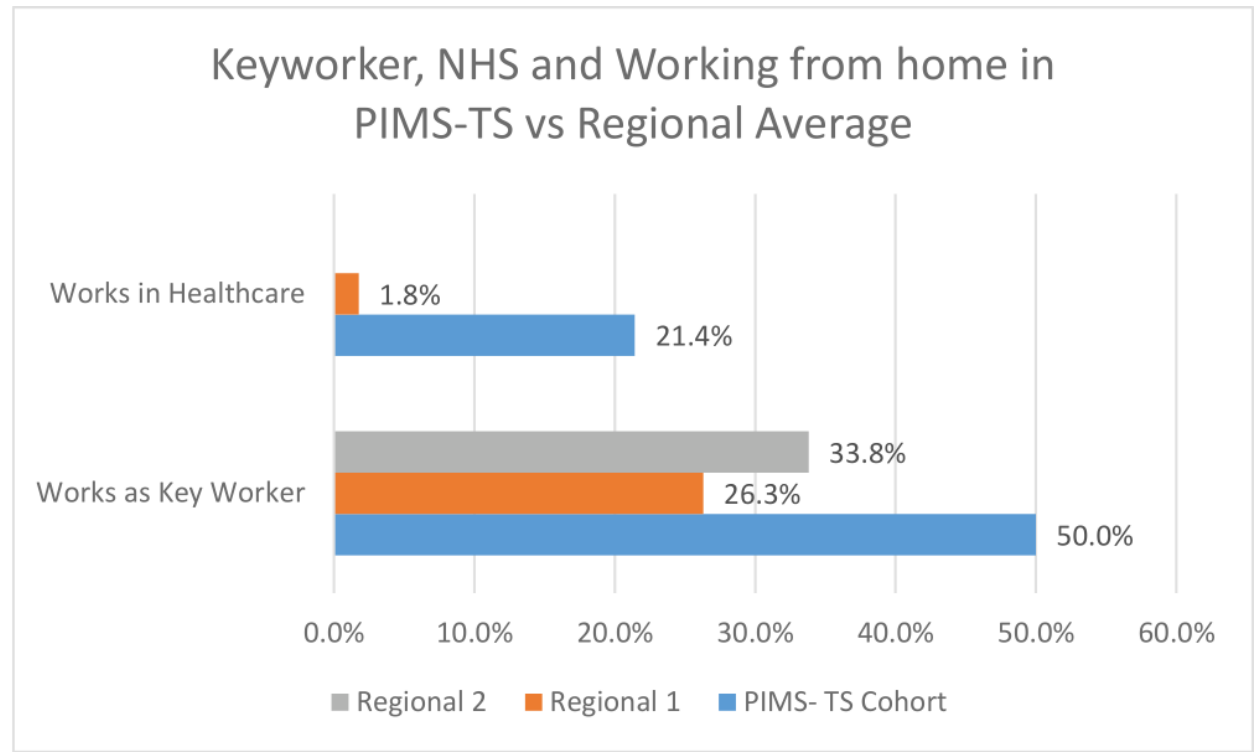

Figure 2 Key worker/healthcare worker family member in PIMS-TS and comparator populations. Key worker regional comparison: from lowest (Richmond, 1) and highest (Bromley, 2); healthcare comparison England from NHS England workforce data ${ }^{21}$; key worker data from ONS. ${ }^{18}$ NHS, National Health Service; ONS, Office for National Statistics; PIMS-TS, Paediatric Inflammatory Multisystem Syndrome, Temporally associated with SARS-CoV-2.

\section{Ethnicity, profession, socioeconomics and PIMS-TS}

Patients from black ethnic groups made up 56\% of the PIMS-TS cohort from the hospital referral region (table 2), whereas the local population has $11 \%$ of children from black ethnic groups. For this group, there was over a 15 -fold increase in PIMS-TS risk (OR 15.7, 95\% CI 8.6 to 28.7). The populations of Asian and other ethnicity groups were also observed to have elevated risk (ORs 4.0 and 11.2, respectively; table 2). The OR of incidence of PIMS-TS in patients from black ethnic groups was higher than the OR of adult COVID-19 infection or hospitalisation (table 3).

Twenty-one per cent and 34\% of our patients were living in postcodes attributed to the most deprived quintiles (1 and
2, respectively); $7 \%$ lived in quintile 5 . Relative to the least deprived quintile, we estimate a nearly fivefold increase in risk for those living in quintiles 1 and 2 (ORs 5.2 and 4.7, respectively) and an over threefold risk in quintile 3 (OR 3.5).

Key worker families made up $50 \%$ of the total cohort (figure 2), with 21\% working in healthcare. In the referring boroughs, $26.3 \%-33.8 \%$ of the working age population are key workers (ONS data). ${ }^{20}$ Data on the number of children living with one or more key workers were not available for comparison. Patients presented from a diverse range of urban and rural areas in the referring region, although predominantly from South West London (figure 3).

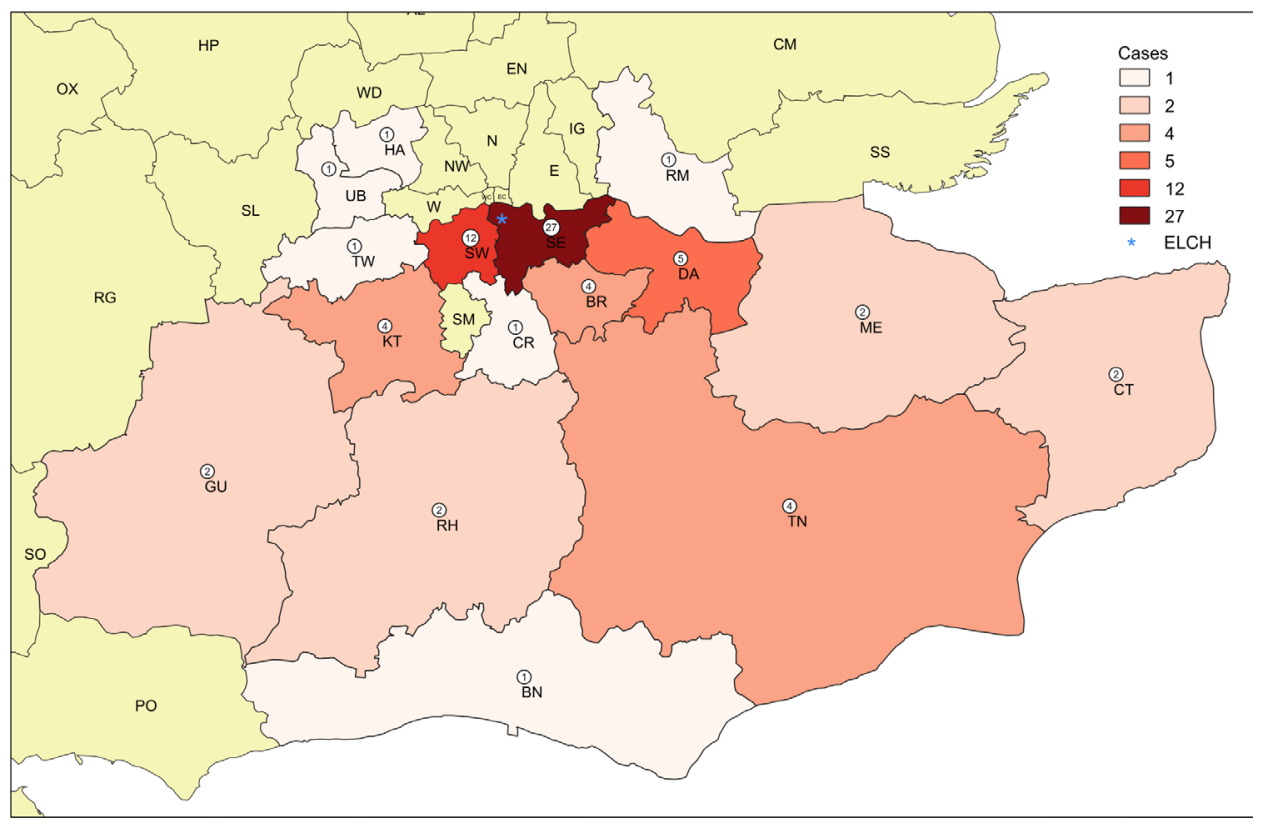

Figure 3 Geographical representation of PIMS-TS cohort by number of cases and district. Adapted with permission from GB Maps. UK Postcode Maps and Vector Editable Outline Postal Code Maps, 2020, published at: www.GBMaps.com (accessed 17 July 2020). PIMS-TS, Paediatric Inflammatory Multisystem Syndrome, Temporally associated with SARS-CoV-2. 


\begin{tabular}{|c|c|c|c|c|c|c|}
\hline Ethnicity & White & Black & Asian & Mixed & Other & Total \\
\hline Length of stay (days) - median (IQR) & $6(3)$ & $8(4)$ & $6(3)$ & $4(1.5)$ & $10(5)$ & $7(4)$ \\
\hline PICU admission, a/b (\%) & $10 / 18(56)$ & 28/38 (74) & $4 / 7(57)$ & $1 / 4(25)$ & $3 / 3(100)$ & $46 / 70(66)$ \\
\hline Invasive ventilation, $\mathrm{a} / \mathrm{b}(\%)$ & $0 / 18(0)$ & 9/38 (24) & $0 / 7(0)$ & $0 / 4(0)$ & $1 / 3(33.3)$ & $10 / 70(14)$ \\
\hline Inotropes, a/b (\%) & $4 / 18(22)$ & $21 / 38(55)$ & $3 / 7(43)$ & $1 / 4(25)$ & $3 / 3(100)$ & $32 / 70(46)$ \\
\hline IMD quintile & 1 & 2 & 3 & 4 & 5 & Total \\
\hline Length of stay (days) - median (IQR) & $9(6)$ & $7.5(4)$ & $6.5(4)$ & $4(2)$ & $6(1)$ & $7(4)$ \\
\hline PICU admission, a/b (\%) & $11 / 15(73)$ & $17 / 24(71)$ & $12 / 18(67)$ & $3 / 8(38)$ & $3 / 5(60)$ & $46 / 70(66)$ \\
\hline Invasive ventilation, a/b (\%) & $4 / 15(27)$ & 4/24 (17) & $2 / 18(11)$ & $0 / 8(0)$ & $0 / 5(0)$ & $10 / 70(14)$ \\
\hline Inotropes, a/b (\%) & $10 / 15(67)$ & $12 / 24(50)$ & $7 / 18(39)$ & $1 / 8(13)$ & $2 / 5(40)$ & $32 / 70(46)$ \\
\hline
\end{tabular}

\section{Social factors and clinical severity}

Clinical markers of severity are presented by ethnicity group and IMD status (table 4). The median stay was 7 days, $14.3 \%$ required ventilation and $45.7 \%$ required inotropes.

Patients in the black ethnic group were observed to have significantly longer length of stay (OR 1.38, 95\% CI 1.04 to 1.82 ; table 5, figure 4 ), with adjustment for IMD quintile, where IMD was treated as a linear covariate. The results were comparable when IMD was treated as an ordinal covariate (see online supplemental appendix). Comparing regression models fit with and without ethnic group, including ethnic group in the regression model significantly improves model fit (when IMD quintile fit as a linear covariate: $61 \mathrm{vs} 65 \mathrm{df}$, likelihood ratio test, $\mathrm{p}=0.01$; IMD quintile fit as ordinal covariate: 58 vs $62 \mathrm{df}$, likelihood ratio test $\mathrm{p}=0.03$ ).

For PICU admission and inotrope use, no significant associations were observed with any of the independent variables, and including ethnic group in the regression model did not significantly improve model fit $(p=0.77, p=0.33$, respectively, with IMD treated as a linear covariate).

Nine out of 10 invasively ventilated patients were from black ethnic groups. The results presented here are for models where IMD quintile was treated as a linear variable. (When IMD quintile was treated as an ordinal variable, the CIs on the estimates for the IMD coefficients were so wide as to render the estimates meaningless. See online supplemental appendix for further discussion.) No significant associations were observed between ventilation and any of the independent variables (table 6). However, including ethnic group significantly improved model fit (64 vs $65 \mathrm{df}$, likelihood ratio test $\mathrm{p}=0.047$ ).

For length of stay, ventilation and inotropes, the regression models without ethnicity show a significant association between IMD quintile (treated as a linear covariate) and each outcome (tables 5 and 6 , and online supplemental appendix). When ethnicity is added to the models, these associations are attenuated and no longer significant.

\section{DISCUSSION}

\section{Principal findings}

We observed that children from black, Asian and other ethnic groups or from deprived IMD quintiles are more likely to have PIMS-TS in a cohort in South East England, though it remains a rare consequence of COVID-19. Children from black ethnic groups in our cohort had longer hospital stays. Ethnicity was associated with the need for ventilation. Children from deprived IMD quintiles had longer hospital stays and were more likely to need ventilators, though this was attenuated when ethnicity was included. A high proportion of children with PIMS-TS were living with a key worker. The disparity in PIMS-TS observed between black and white ethnic groups is greater than that observed for adult COVID-19 infection or hospitalisation (table 3). These observations should be noted with caution given the rare and novel nature of the disease and would benefit from further multicentre prospective analysis as understanding of this disease develops further.

The difference in risk between children in black and white ethnic groups is greater in PIMS-TS than in Kawasaki disease. ${ }^{14} 15$ Our study is, to our knowledge, the first to compare ethnicity with the population risk, to evaluate key worker status and to control for confounders.

\section{Strengths and weaknesses}

This is the largest UK cohort of patients, spanning a diverse region of urban and rural South East England, although the disease remains rare, which limits the interpretation of findings. Generalisability would be improved by cross-centre analysis. ELCH was the referral hospital for new patients in the catchment area

Table 5 Estimated regression coefficients for length of stay (log transformed)

\begin{tabular}{|c|c|c|c|c|c|c|}
\hline & \multicolumn{3}{|c|}{ Including ethnicity } & \multicolumn{3}{|c|}{ Model excluding ethnicity } \\
\hline & Estimate & $95 \% \mathrm{Cl}$ & P value & Estimate & $95 \% \mathrm{Cl}$ & $P$ value \\
\hline Asian & 0.944 & 0.643 to 1.39 & 0.765 & & & \\
\hline Black & 1.38 & 1.04 to 1.82 & 0.0252 & & & \\
\hline Mixed & 0.706 & 0.442 to 1.13 & 0.142 & & & \\
\hline Other & 1.46 & 0.853 to 2.5 & 0.164 & & & \\
\hline IMD quintile & 0.913 & 0.827 to 1.01 & 0.0727 & 0.854 & 0.777 to 0.939 & 0.00141 \\
\hline BMI & 0.964 & 0.939 to 0.989 & 0.00588 & 0.975 & 0.95 to 1 & 0.0592 \\
\hline Age (months) & 1 & 1 to 1 & 0.0368 & 1 & 1 to 1 & 0.0625 \\
\hline Gender (male) & 1.05 & 0.833 to 1.33 & 0.656 & 1.04 & 0.812 to 1.33 & 0.747 \\
\hline
\end{tabular}

Likelihood ratio test when including ethnicity versus not including ethnicity $p=0.01$.

BMI, body mass index; IMD, Index of Multiple Deprivation. 

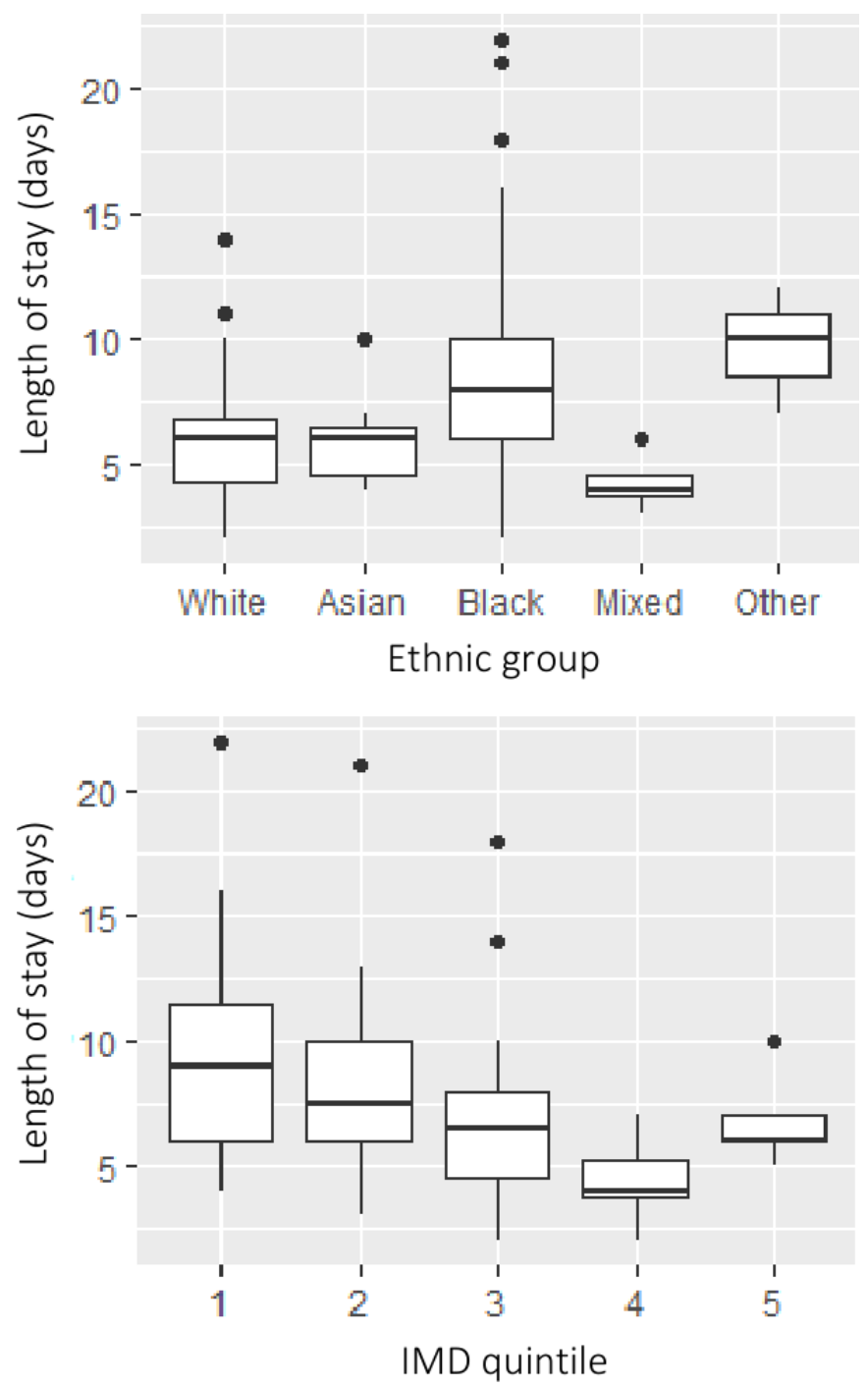

Figure 4 Length of stay by ethnic group and IMD quintile. figure S.4 clinical features of patients according to $C D C$ versusWHO versus $R C P C H$ diagnostic criteria. CDC, Centers for Disease Control and Prevention; IMD, Index of Multiple Deprivation; RCPCH, Royal College of Paediatrics and Child Health.

as it had a tertiary cardiac and intensive care service, although a minority may have been missed or managed elsewhere; on surveying area PICUs, we are aware of only two patients in the network that were not subsequently referred (personal communication, Deep, Nov 2020). Subjective judgement of clinical features enables observer bias. Our clinical team does not reflect the ethnicity of the patients; we were unable to measure bias resulting from this difference. Demographic change is possible; census data are from 2011. While we have modelled for corrections in age, we may overestimate the relative risk based on black ethnic groups given migration during this period. ${ }^{9}$

The rare nature of the disease and small sample sizes limit generalisability and statistical testing. We assessed confounders such as socioeconomic deprivation, but not contributors such as housing. Many limitations of ethnicity categorisation are discussed elsewhere. ${ }^{26}$

The lack of consistency and the emergent nature of the PIMS-TS definitions remain limitations, and further research is needed to clarify diagnostic criteria. Thirteen patients did not meet $\mathrm{RCPCH}$ criteria yet had similar clinical, laboratory and cardiac findings (online supplemental appendix). Factors contributing to this discrepancy included SARS-CoV2 testing and coinfection, suggesting a need for further research.

\section{Implications}

It is likely that the observed higher risk in children from ethnic minorities is due to an interplay of factors. Variations in expression of the ACE 2 receptor, differences in lung function, vitamin $\mathrm{D}$ status and metabolic comorbidities have been cited, although with only few data, as potential biological factors. ${ }^{11}{ }^{27}$ However, it is social factors that are more amenable to intervention, underlined by the association we found with deprivation. Some people in certain ethnic minority groups may be socioeconomically disadvantaged, in poor housing, overcrowded with cohabiting families, and low-paid essential jobs, rendering social distancing difficult. ${ }^{11}$ Cultural barriers have been cited, including language barriers, lack of trust in medical professionals and lack of culturally specific health promotion. ${ }^{28}$ Notably, pandemic public health control measures had a differential impact in different ethnic minority groups. ${ }^{29}$ Structural barriers to healthcare access include 'hostile environment' measures, such as NHS charging based on migration status, which contributes to delay in people in BAME ethnic groups with insecure immigration status (eg, Windrush families) ${ }^{30}$ and wider communities. ${ }^{31}$ The RCPCH alongside other medical colleges has called for charging to be suspended ${ }^{32}$ to avoid the effects of delayed presentation during the COVID-19 pandemic. $^{33} 34$

The added risk to families in BAME groups, particularly in key worker families, is noteworthy. People from BAME groups are more likely to work in key worker professions, particularly healthcare, making up $48 \%$ of staff in parts of London. ${ }^{35}$ Key workers including healthcare workers from BAME groups have had higher rates of COVID-19 and COVID-19 related deaths. ${ }^{3637}$ Doctors from ethnic minority groups reportedly felt less confident to raise concerns over personal protective equipment and more pressured to perform consultations that potentially put themselves at risk, compared with white colleagues. ${ }^{37}$

Key stakeholders including British Association for Physicians of Indian Origin (BAPIO), Muslim Council of Britain (MCB)

Table 6 Estimated regression coefficients for invasive ventilation

\begin{tabular}{|c|c|c|c|c|c|c|}
\hline & \multicolumn{3}{|c|}{ Complete model } & \multicolumn{3}{|c|}{ Model excluding ethnicity } \\
\hline & Estimate & $95 \% \mathrm{Cl}$ & $P$ value & Estimate & $95 \% \mathrm{Cl}$ & $P$ value \\
\hline Ethnicity (black) & 10.3 & 1.4 to 224 & 0.0502 & & & \\
\hline IMD quintile & 0.61 & 0.223 to 1.45 & 0.293 & 0.426 & 0.174 to 0.865 & 0.0339 \\
\hline BMI & 0.833 & 0.661 to 0.999 & 0.0753 & 0.873 & 0.702 to 1.04 & 0.169 \\
\hline Age (months) & 1.01 & 0.993 to 1.03 & 0.303 & 1.01 & 0.992 to 1.02 & 0.418 \\
\hline Gender (male) & 1.04 & 0.198 to 6.28 & 0.964 & 0.81 & 0.165 to 4.58 & 0.798 \\
\hline
\end{tabular}

Likelihood ratio test when including ethnicity vs not including ethnicity $p=0.04722$.

$\mathrm{BMI}$, body mass index; IMD, Index of Multiple Deprivation. 
and British International Doctors Association (BIDA) ${ }^{38} 39$ have called for: ethnicity-based risk assessments for key worker staff (BIDA), not asking retired staff in BAME ethnic groups to return to high-risk areas (BAPIO), disaggregation of data to include ethnicity, faith and socioeconomics (Muslim Doctors Association), research into lived experiences (BAPIO), research into structural racism's contribution (MCB) and an inquiry into health inequalities in COVID-19. The risk to people working outside the home, including key workers and those without a choice, requires further research. In light of concerns about inequitable uptake of COVID-19 vaccines, a coalition of local authorities, medical organisations and charities have called for an end to 'hostile environment' policies to ensure universal access across all groups.

The risk to children living in high deprivation areas should be considered, particularly given reported increases of 600000 children in poverty since 2012, and the interplay between deprivation and ethnicity risk in our data. ${ }^{40}$ These data highlight the importance of action that addresses the wider social determinants of health. ${ }^{41}$

The higher risk to children in certain ethnic groups and deprivation quintiles has implications for clinicians, regarding risk stratification, improving diagnostic accuracy and timeliness. For policymakers, it is important to note that, despite finding these associations, any preventive interventions, particularly those at a population level, must be proportionate to the relatively rare incidence of PIMS-TS. While this study adds further weight to the increasing calls for population measures protecting BAME, key worker and more deprived groups, it should be taken in the context of the overwhelming rarity with which children in general develop COVID-19 related complications, in comparison with adult patients. Decisions must also be balanced against the wider harms that may come to children as a result of measures to reduce COVID-19 transmission. ${ }^{42}$

\section{Unanswered questions}

These data raise important questions including: the mechanisms for different risks, contribution of household factors, delays in presentation and reasons for this, structural factors contributing to these inequalities and treatment implications.

\section{Author affiliations \\ 'Department of Paediatric Infectious Disease, Evelina London Children's Healthcare, London, UK \\ ${ }^{2}$ Kellogg College, University of Oxford, Oxford, UK \\ ${ }^{3}$ Department of Women and Children's Health, King's College London, London, UK ${ }^{4}$ Department of Paediatric Rheumatology, Evelina London Children's Healthcare, London, UK \\ ${ }^{5}$ Department of General Paediatrics, Evelina London Children's Healthcare, London, UK \\ ${ }^{6}$ Department of Paediatric Intensive Care, Evelina London Children's Healthcare, London, UK \\ ${ }^{7}$ Department of Paediatric Cardiology, Evelina London Children's Healthcare, London, UK}

Twitter Alysha McIntosh @alyshapmcintosh, Ronny Cheung @cheungronny and Jon Lillie @DrJonLillie

Acknowledgements The authors would like to acknowledge and sincerely thank the patients and their families whose experiences informed this work, the large range of clinicians in the Paediatric Inflammatory Multisystem Syndrome, Temporally associated with SARS-CoV-2 (PIMS-TS) study group and Evelina London Children's Hospital (ELCH) wards who have taken part in the management of this novel condition. Thanks to the team at GBMaps for their help and use of their figure. Particular thanks are due to Dr Julia Kenny, Dr Ingrid Wolfe, Dr James Wong, Dr Moira Cheung, Professor Baba Inusa and Dr Ming Lim for their informal and institutional support and advice. This work is a collaboration with the Institute of Women's and Children's Health (IWCH). The IWCH is part of King's Health Partners, the Academic Health Sciences Centre pioneering collaboration between King's
College London, and Guy's and St Thomas', King's College Hospital and South London and Maudsley NHS Foundation Trusts.

Collaborators Julia Kenny; Kevin Meesters; Nuria Martinez-Alier; Alicia Demirjian; Marc Tebruegge; Alejandro Alonso; Tish Shah; Marie White; Anna Finemore; Fran Blackburn; Emma Parish; Bianca Tiesman; Nadia Trecchi; John Jackman; Mark Butler; Rohana Ramachandran; Alice Roueche; Chloe Macaulay; Claire Lemer; Debbie Sobande; Ajanta Kamal; Nick Wilkinson; Sara Arenas; Nanna Christiansen; Mandy Wan; Asia Rashed; Sujeev Mathur; James Wong; Paraskevi Theocharis; Kirsty Stewart; Saleha Kabir; Kelly Peacock; Kuberan Pushparajah; Alex Savis; Will Regan; Emma Pascall; Aoife Cleary; Mirasol Uy; Hannah Heard; Michael Carter; Shane Tibby; Shelley Riphagen; Marilyn MacDougall; Ben Griffths; Gareth Waters; Federico Minen; Andrew Nyman; Miriam Fine Goulden; Ken MacGruer; Mario Sa; Ming Lim; Susan Bryne; Jill Cadwgan; JP Lim; Rahul Singh; Shan Tang; Dan Lumsden; Sam Senior; Sarah McMurtrie; Emily.Foster; Matthew Norridge; Stephanie Emberson; Stacey Marr; Victoria Felton; Chris Reid; Shazia Adalat; Ramnath Balasubramanian; Helen Jones; Jay Alamelu; Baba Insua; Jeff Lam Ho Pui; Jo Howard; David Rees; Maria Pelidis; Moira Cheung; Rui Santos; Haran Jogeesvaran; Heba Elbaaly; Catriona Reid; Dipalee Durve; Shema Hameed; Carsten Flohr; Danielle Greenblatt; Cristina Psomadakis; Emma Craythorne; Vanessa Albert; lain Yardley; Kirsty Brennan; Ingrid Wolfe; David Edwards; Mike Harrison; Ben Baig; Deborah Woodman; Harriet Conniff ; Anne Gordon; Jonathan Edgeworth; Gaia Nebbia; Rahul Batra; Suzanne Pickering; Gilberto Betancor; Harry Wilson; Adrian Signell; and Rui Pedro Galão.

Contributors JB conceived and designed the project, analysed and interpreted the data and drafted and revised the manuscript. JF designed the project, led the analysis and interpretation of data, and drafted and revised the manuscript. Thei contribution to the paper is equal. JB, AO, MF, XG, IG, AM, JT and AS contributed to the acquisition of all data and the design, analysis and interpretation of data and revised the manuscript; CRC, JL and VS contributed to the design, analysis and interpretation of data and revised the manuscript; JH and OM conceived the project, designed the project and analysis and revised the manuscript; all authors approved the final version and agreed to be accountable for all aspects of the work.

Funding The authors have not declared a specific grant for this research from any funding agency in the public, commercial or not-for-profit sectors.

Map disclaimer The depiction of boundaries on this map does not imply the expression of any opinion whatsoever on the part of BMJ (or any member of its group) concerning the legal status of any country, territory, jurisdiction or area or of its authorities. This map is provided without any warranty of any kind, either express or implied.

\section{Competing interests None declared.}

Patient consent for publication Not required.

Ethics approval This project was registered with the approval of the ELCH audit and service evaluation team.

Provenance and peer review Not commissioned; externally peer reviewed.

Data availability statement Data are available on reasonable request. All data are available on reasonable request, including the primary data and the statistical analysis plans.

Supplemental material This content has been supplied by the author(s). It has not been vetted by BMJ Publishing Group Limited (BMJ) and may not have been peer-reviewed. Any opinions or recommendations discussed are solely those of the author(s) and are not endorsed by BMJ. BMJ disclaims all liability and responsibility arising from any reliance placed on the content. Where the content includes any translated material, BMJ does not warrant the accuracy and reliability of the translations (including but not limited to local regulations, clinical guidelines, terminology, drug names and drug dosages), and is not responsible for any error and/or omissions arising from translation and adaptation or otherwise.

Open access This is an open access article distributed in accordance with the Creative Commons Attribution Non Commercial (CC BY-NC 4.0) license, which permits others to distribute, remix, adapt, build upon this work non-commercially, and license their derivative works on different terms, provided the original work is properly cited, appropriate credit is given, any changes made indicated, and the use is non-commercial. See: http://creativecommons.org/licenses/by-nc/4.0/.

\section{ORCID iDs}

Jonathan Broad http://orcid.org/0000-0003-4710-2904

Ronny Cheung http://orcid.org/0000-0001-7093-0447

Jon Lillie http://orcid.org/0000-0003-1776-5184

Owen Miller http://orcid.org/0000-0003-1448-1012

\section{REFERENCES}

1 Zimmermann P, Curtis N. Coronavirus infections in children including COVID-19: an overview of the epidemiology, clinical features, diagnosis, treatment and prevention options in children. Pediatr Infect Dis J 2020;39:355. 
2 Bhopal SS, Bagaria J, Olabi B, et al. COVID-19 deaths in children: comparison with alland other causes and trends in incidence of mortality. Public Health 2020;188:32-4.

3 Whittaker E, Bamford A, Kenny J, et al. Clinical characteristics of 58 children with a pediatric inflammatory multisystem syndrome temporally associated with SARSCoV-2. JAMA 2020;324:259.

4 RCPCH. Guidance: paediatric multisystem inflammatory syndrome temporally associated with COVID-19. London: Royal College of Paediatrics and Child Health, 2020.

5 CDC. Multisystem inflammatory syndrome in children (MIS-C) associated with coronavirus disease 2019 (COVID-19). Center for Disease Control and Prevention, 2020

6 WHO. Multisystem inflammatory syndrome in children and adolescents with COVID-19. World Health Organisation, 2020.

7 Verdoni L, Mazza A, Gervasoni A, et al. An outbreak of severe Kawasaki-like disease at the Italian epicentre of the SARS-CoV-2 epidemic: an observational cohort study. The Lancet 2020;395:1771-8

8 Toubiana J, Poirault C, Corsia A, et al. Kawasaki-like multisystem inflammatory syndrome in children during the covid-19 pandemic in Paris, France: prospective observational study. BMJ 2020:369:m2094.

9 PHE. COVID-19: review of disparities in risks and outcomes. Public Health England, 2020.

10 Pan D, Sze S, Minhas JS, et al. The impact of ethnicity on clinical outcomes in COVID-19: a systematic review. EClinica/Medicine 2020;23:100404.

11 Kirby T. Evidence mounts on the disproportionate effect of COVID-19 on ethnic minorities. Lancet Respir Med 2020;8:547-8.

12 Davies P, Evans C, Kanthimathinathan HK, et al. Intensive care admissions of children with paediatric inflammatory multisystem syndrome temporally associated with SARS CoV-2 (PIMS-TS) in the UK: a multicentre observational study. Lancet Child Adolesc Health 2020;4:669-77.

13 Dufort EM, Koumans EH, Chow EJ, et al. Multisystem inflammatory syndrome in children in New York state. N Engl J Med 2020;383:347-58.

14 Harnden A, Mayon-White R, Perera R, et al. Kawasaki disease in England: ethnicity, deprivation, and respiratory pathogens. Pediatr Infect Dis J 2009;28:21-4.

15 Davies S, Sutton N, Blackstock S, et al. Predicting IVIg resistance in UK Kawasak disease. Arch Dis Child 2015:100:366-8.

16 von Elm E, Altman DG, Egger M, et al. The strengthening the reporting of observational studies in epidemiology (STROBE) statement: guidelines for reporting observational studies. Ann Intern Med 2007;147:573-7.

17 McCrindle BW, Rowley AH, Newburger JW, et al. Diagnosis, treatment, and long-term management of Kawasaki disease: a scientific statement for health professionals from the American heart association. Circulation 2017;135:e927-99.

18 Gov UK. The English indices of deprivation, 2019.

19 Gov UK. Population of England and Wales, 2011

20 ONS. Coronavirus and keyworkers in the UK. Office for National Statistics, 2020.
21 Lassale C, Gaye B, Hamer M, et al. Ethnic disparities in hospitalisation for COVID-19 in England: the role of socioeconomic factors, mental health, and inflammatory and pro-inflammatory factors in a community-based cohort study. Brain Behav Immun 2020;88:44-9.

22 Gov UK. Coronavirus (COVID-19) in the UK. U.K. Gov, 2020.

23 Digital N. NHS workforce statistics, 2020.

24 Team RC. R: a language and environment for statistical computing. Vienna, Austria, 2013

25 Team R. RStudio: Integrated Development for R [Internet]. Boston, MA: RStudio, Inc, 2019.

26 Lee C. "Race" and "ethnicity" in biomedical research: how do scientists construct and explain differences in health? Soc Sci Med 2009;68:1183-90.

27 Laird E, Rhodes J, Kenny RA. Vitamin D and inflammation: potential implications for severity of Covid-19. Ir Med J 2020;113:P81

28 Abuelgasim E, Saw LJ, Shirke M, et al. COVID-19: unique public health issues facing black, Asian and minority ethnic communities. Curr Prob/ Cardiol 2020;45:100621.

29 Martin CA, Jenkins DR, Minhas JS, et al. Socio-demographic heterogeneity in the prevalence of COVID-19 during lockdown is associated with ethnicity and household size: results from an observational cohort study. EClinicalMedicine 2020;25:100466.

30 Potter JL, Burman M, Tweed CD, et al. The NHS visitor and migrant cost recovery programme - a threat to health? BMC Public Health 2020;20:1-9.

31 Murphy L, Broad J, Hopkinshaw B, et al. Healthcare access for children and families on the move and migrants. BMJ Paediatr Open 2020;4:e000588.

32 AOMRC. NHS charges to overseas visitors regulations. Academy of Medical Royal Colleges, 2019

33 DOTW. Letter to home Secretary and Secretary of state for health and social care calling for suspension of NHS charging regulations. Doctors of the World, 2020

34 Medact. Migrants access to healthcare during the coronavirus crisis. London, 2020.

35 HF. Black and minority ethnic workers make up a disproportionately large share of key worker sectors in London. Health Foundation, 2020.

36 Cook TK. Exclusive: deaths of NHS staff from covid-19 analysed. Health Serv Res 2020.

37 Association BM. Bame doctors hit worse by lack of PPE, 2020.

38 Daga S, Chakravorty I, Bamrah JS, et al. Self-reported occupational risk for COVID-19 in hospital doctors from black asian \& minority ethnic communities in UK. Phy 2020;6.

39 Gov UK. COVID-19 understanding the impact on BamE communities, 2020.

40 Gov UK. Monitoring social mobility 2013 to 2020: social mobility Commission, 2020.

41 RCPCH. Poverty and child health-views from the frontline. Royal College of Paediatrics and Child Health, 2017.

42 Crawley E, Loades M, Feder G, et al. Wider collateral damage to children in the UK because of the social distancing measures designed to reduce the impact of COVID-19 in adults. BMJ Paediatr Open 2020;4:e000701. 